\title{
Upregulation of kallikrein-related peptidase 5 is associated with the malignant behavior of colorectal cancer
}

\author{
YANHUA WU ${ }^{1 *}$, YINGJIAN CHEN ${ }^{1 *},{\text { QING } \text { LI }^{2}, \text { YANWEN GONG }}^{1}$, \\ XIAOHONG LIU ${ }^{3}$, LIQUAN BI ${ }^{3}$ and CHENGJIN HU ${ }^{1}$ \\ ${ }^{1}$ Department of Laboratory Medicine, General Hospital of Jinan Military Command, Jinan, Shandong 250031; \\ ${ }^{2}$ Department of Clinical Laboratory, Zaozhuang Municipal Hospital, Zaozhuang, Shandong 277102; \\ ${ }^{3}$ Department of Pathology, General Hospital of Jinan Military Command, Jinan, Shandong 250031, P.R. China
}

Received March 17, 2015; Accepted February 22, 2016

DOI: $10.3892 / \mathrm{mmr} .2016 .5516$

\begin{abstract}
Kallikrein-related peptidase 5 (KLK5) is a serine protease that has exhibited upregulated expression in numerous types of human cancer. The present study assessed KLK5 expression in colorectal cancer (CRC) tissues, in order to determine its association with clinicopathological data and prognosis. The mRNA and protein expression levels of KLK5 were detected using reverse transcription-quantitative polymerase chain reaction, immunohistochemistry and enzyme-linked immunosorbent assay, respectively. KLK5 expression was detected in 48 paraffin-embedded tumor tissue samples and corresponding tumor-free areas within the same specimens, 40 paired normal and CRC frozen tissues, and serum samples from 70 patients with CRC (including 38 serum samples taken pre- and post-surgery) and 53 healthy individuals. The results demonstrated that KLK5 protein was strongly expressed in CRC; however, its expression was hardly detected in the matched normal mucosal tissue. The KLK5 mRNA expression levels were significantly upregulated in CRC tissues compared with the paired normal tissues, and were higher in Dukes' stage $\mathrm{C} / \mathrm{D}$ cancer than in stage $\mathrm{A} / \mathrm{B}$ $(\mathrm{P}<0.001)$. Furthermore, sera from patients with $\mathrm{CRC}$ exhibited increased KLK5 levels, as compared with that of healthy volunteers (878.02 vs. 391.07 pg/ml; P<0.001). Serum KLK5 levels were also significantly higher in patients prior to surgery compared with post-surgery $(909.48 \pm 536.72$ vs $644.00 \pm 522.87 \mathrm{pg} / \mathrm{ml} ; \mathrm{P}<0.001)$. In addition, increased serum KLK5 levels were associated with CRC lymph node or distant metastasis $(\mathrm{P}=0.003)$, tumor-lymph node-metastasis stage
\end{abstract}

Correspondence to: Dr Chengjin Hu, Department of Laboratory Medicine, General Hospital of Jinan Military Command, 25 Shifan Road, Jinan, Shandong 250031, P.R. China

E-mail: hcj6289@163.com

${ }^{*}$ Contributed equally

Key words: kallikrein-related peptidase 5, colorectal cancer, tumor markers
$(\mathrm{P}=0.004)$, and Dukes' stage $(\mathrm{P}=0.005)$. The results of the present study indicated that the mRNA and protein expression levels of KLK5 were significantly upregulated in CRC tissues and sera, and were associated with an advanced tumor stage. Further studies may identify KLK5 as a biomarker of CRC recurrence or treatment response.

\section{Introduction}

Colorectal cancer (CRC) is the third most common type of human malignancy, and the second leading cause of cancer-associated mortality worldwide (1). The incidence of CRC has been increasing in Asian countries, including China, Korea, Japan, and Singapore. The reason for this increasing incidence is currently unclear; however, demographic trends and adaptation to a westernized lifestyle, particularly with regards to factors such as diet, may have a role in the increased incidence of CRC in these countries (2). During the past few decades, there have been numerous advances in CRC research, including early detection, prevention by adaptation to a healthier lifestyle, and improved treatment strategies; however, a high percentage of patients with CRC still develop advanced stages of the disease and tumor metastasis (3). Therefore, the identification and evaluation of biomarkers for the prediction of disease progression, prognosis, and treatment response may help physicians effectively treat and control the spread of cancer in these patients. To date, clinicopathological characteristics, including CRC tumor-lymph node-metastasis (TNM) stage, differentiation grade, lymph node metastasis, invasion to other tissue or structures, and tumor size, have been used to evaluate treatment selection and prognosis of patients with CRC. Various biomarkers, such as carcinoembryonic antigen (CEA) and carbohydrate antigen (CA)19-9, have previously been identified and evaluated with regards to the diagnosis, and prediction of tumor recurrence or treatment response (4-6). However, these biomarkers are not without fault, due to the lack of specificity and sensitivity; therefore, more research is required to identify novel serum-based tumor markers that may be used screen the general or high-risk population for early diagnosis of $\mathrm{CRC}$, or predict CRC prognosis and treatment response (4). 
Kallikrein-related peptidase 5 (KLK5), which is one of 15 kallikrein subfamily members, is a serine protease located on chromosome 19 (7). Functionally, KLK5 is usually expressed in the epidermis and regulates cell shedding in conjunction with KLK7 and KLK14 (7-9). KLK5 can become activated from the secreted pro-KLK5, in order to activate several other KLKs, such as KLK2, $-3,-6,-7,-11,-12$ and -14 (10). In addition, KLK5 proteolytic activity is able to target metalloproteases and extracellular matrix components, including collagens, fibronectin, and laminin $(11,12)$. Previous studies have demonstrated that KLK5 is upregulated in numerous types of human cancer (7,13-19). Indeed, kallikrein-mediated extracellular proteolysis is important in several facets of cancer development, including regulation of tumor growth, invasion, metastasis, and angiogenesis (20). A previous study demonstrated that altered expression of KLKs is associated with cancer development and diagnosis, and may therefore be considered a useful prognostic marker for prostate, breast, and ovarian cancer (13). In CRC, KLK5 protease accumulates in tumor tissues and is associated with an unfavorable outcome for patients (21). The present study further assessed KLK5 expression in CRC tissue specimens and serum samples from patients with CRC using reverse transcription-quantitative polymerase chain reaction (RT-qPCR), immunohistochemistry, and enzyme-linked immunosorbent assay (ELISA). In addition, the association between KLK5 expression and clinicopathological parameters of the patients was determined.

\section{Materials and methods}

Study subjects. The present study collected 40 fresh CRC and paired normal tissues from patients who had undergone surgical resection of CRC lesions at the Department of Surgery, General Hospital of Jinan Military Command (Jinan, China) between November 2006 and May 2012. Among these patients, there were 23 men and 17 women with a median age of 58 years (range, 31-77 years). CRC was diagnosed and graded according to the revised World Health Organization grading system and was staged according to the Dukes' operative staging system. In particular, 4/40 cases of CRC (10\%) were well-differentiated, $27 / 40(67.5 \%)$ were moderately differentiated, and 9/40 (22.5\%) were poorly differentiated; whereas $10 / 40$ cases of CRC (25\%) were at stage A, 11/40 (27.5\%) were at stage $\mathrm{B}, 17 / 40(42.5 \%)$ were at stage $\mathrm{C}$, and $2 / 40(5 \%)$ were at stage D (Dukes' stages). A total of 17 patients exhibited regional lymph node tumor metastasis, and 2 patients exhibited tumor metastasis to the liver.

In addition, 48 paraffin-embedded CRC tissue samples were obtained from 28 male and 20 female patients with a median age of 60 years and a range of 22-80 years., and serum samples were collected from an additional 70 patients with CRC (Table I), including 38 serum samples taken preand post-surgery, and 53 healthy individuals from the same hospital. The present study was approved by the Medical Ethics Committee of the General Hospital of Jinan Military Command (Jinan, China), and all participants provided written informed consent.

$R T-q P C R$. Total RNA was isolated from the 40 paired normal and tumor frozen tissues using TRIzol reagent
(Invitrogen; Thermo Fisher Scientific, Inc., Waltham, MA, USA), according to the manufacturer's protocol. Frozen samples $(100 \mathrm{mg})$ were homogenated in $1 \mathrm{ml}$ TRIzol, RNA quality and quantity were measured using a LAMBDA Bio UV/VIS Spectrophotometer (PerkinElmer, Inc., Waltham, MA, USA), and RNA was reverse transcribed into cDNA using a real-time qPCR kit (Takara Biotechnology Co., Ltd., Dalian, China), according to the manufacturer's protocol. The SYBR Green qPCR assay was performed to amplify the cDNA samples using a Roche LightCycler 480 II (Roche Diagnostics, Basel, Switzerland). The primers used were as follows: KLK5, forward 5'-AAGGTCCTCCAGTGC TTGAA-3', reverse 5'-CCAACAGACCGGGTGTCTAC-3' (synthesized in our laboratory); and GAPDH, forward 5'-GAA GGTGAAGGTCGGAGTC-3' and reverse 5'-GAAGATGGT GATGGGATTTC-3' (Sango Biotech, Shanghai, China). The qPCR 25- $\mu 1$ reaction mixture consisted of $12.5 \mu 12 \mathrm{X}$ SYBR Premix Ex Taq (Takara Biotechnology Co., Ltd.), $1 \mu 1$ each primer (100 nM), $1 \mu \mathrm{l}$ cDNA and RNase free $\mathrm{H}_{2} \mathrm{O}$ up to $25 \mu \mathrm{l}$. The qPCR conditions were set as follows: Initial denaturation at $95^{\circ} \mathrm{C}$ for $5 \mathrm{~min}$, followed by 40 cycles at $95^{\circ} \mathrm{C}$ for $5 \mathrm{sec}$ and $60^{\circ} \mathrm{C}$ for $10 \mathrm{sec}$, the temperature was then increased from 65 to $92^{\circ} \mathrm{C}$ to obtain the melting curve, which was used to distinguish specific products from non-specific products or primer dimers. The relative mRNA expression levels of KLK5 were determined by normalization to the endogenous control, GAPDH mRNA, and were calculated using the $2^{-\Delta \Delta C q}$ method as follows: $\triangle \mathrm{Cq}=\mathrm{Cq}$ (mRNA of KLK5) - Cq (mRNA of GAPDH). The $\mathrm{Cq}$ value was the threshold cycle at which fluorescence was detected. Each sample was measured in duplicate and repeated at least once. The KLK5 and GAPDH qPCR products subsequently underwent $1.5 \%$ agarose gel electrophoresis, and were visualized by ethidium bromide staining in order to confirm product size.

Immunohistochemistry. The indirect immunoperoxidase method was used to analyze the KLK5 expression in archived formalin-fixed, paraffin-embedded samples from 48 CRC and matched tumor-free tissues. These tissue samples were used to confirm the RT-qPCR results. For the immunohistochemistry experiments, tissue sections $(4 \mu \mathrm{m})$ were cut from the paraffin blocks, deparaffinized twice in warm xylene (5 min each), and rehydrated through a series of graded alcohol solutions. Endogenous peroxidase activity was blocked with $3 \% \mathrm{H}_{2} \mathrm{O}_{2}$ in methanol for $10 \mathrm{~min}$, and with normal serum for $30 \mathrm{~min}$ at room temperature. Subsequently, tissue sections were incubated with $200 \mu 1$ KLK5 primary antibody at a dilution of 1:400 in phosphate-buffered saline (PBS) at $4^{\circ} \mathrm{C}$ overnight. This KLK5 rabbit polyclonal antibody was generated in our laboratory using recombinant KLK5 protein (22). Immunohistochemical staining of antibodies was performed using the Dako K5007 Envision Plus System (Dako, Glostrup, Denmark). The antibody binding was visualized with a 3,3'-Diaminobenzidine staining prior to a brief counterstaining with Mayer's hematoxylin. In the negative control experiments, the primary antibody was replaced with antibody diluent. The stained tissue sections were reviewed and scored under an Olympus BX53 microscope (Olympus Corporation, Tokyo, Japan) using a semi-quantitative scoring system for both the intensity of the stain and the percentage of positive neoplastic cells (23). 
Table I. Association of serum KLK5 levels with the clinicopathological features of colorectal cancer.

\begin{tabular}{|c|c|c|c|c|}
\hline \multirow[b]{2}{*}{ Characteristics } & \multirow[b]{2}{*}{ Total number } & \multicolumn{2}{|c|}{ Serum KLK5 level } & \multirow[b]{2}{*}{ P-value } \\
\hline & & High & Low/negative & \\
\hline Gender & & & & 0.092 \\
\hline Male & 44 & 33 & 11 & \\
\hline Female & 26 & 17 & 9 & \\
\hline Age & & & & 0.720 \\
\hline$<60$ years old & 33 & 24 & 9 & \\
\hline$\geq 60$ years old & 37 & 26 & 11 & \\
\hline Tumor site & & & & 0.700 \\
\hline Rectum & 49 & 35 & 14 & \\
\hline Colon & 21 & 15 & 6 & \\
\hline Differentiation & & & & 0.890 \\
\hline Well/moderate & 51 & 36 & 15 & \\
\hline Poor & 11 & 6 & 5 & \\
\hline Tumor size & & & & 0.874 \\
\hline$<5 \mathrm{~cm}$ & 32 & 24 & 8 & \\
\hline$\geq 5 \mathrm{~cm}$ & 30 & 23 & 7 & \\
\hline Dukes' stage & & & & 0.005 \\
\hline $\mathrm{A} / \mathrm{B}$ & 37 & 23 & 14 & \\
\hline $\mathrm{C} / \mathrm{D}$ & 28 & 25 & 3 & \\
\hline TNM stage & & & & 0.004 \\
\hline $\mathrm{I} / \mathrm{II}$ & 40 & 26 & 14 & \\
\hline III/IV & 26 & 23 & 3 & \\
\hline Metastasis & & & & 0.003 \\
\hline Absent & 37 & 23 & 14 & \\
\hline Present & 32 & 23 & 9 & \\
\hline
\end{tabular}

TNM, tumor-lymph node-metastasis.
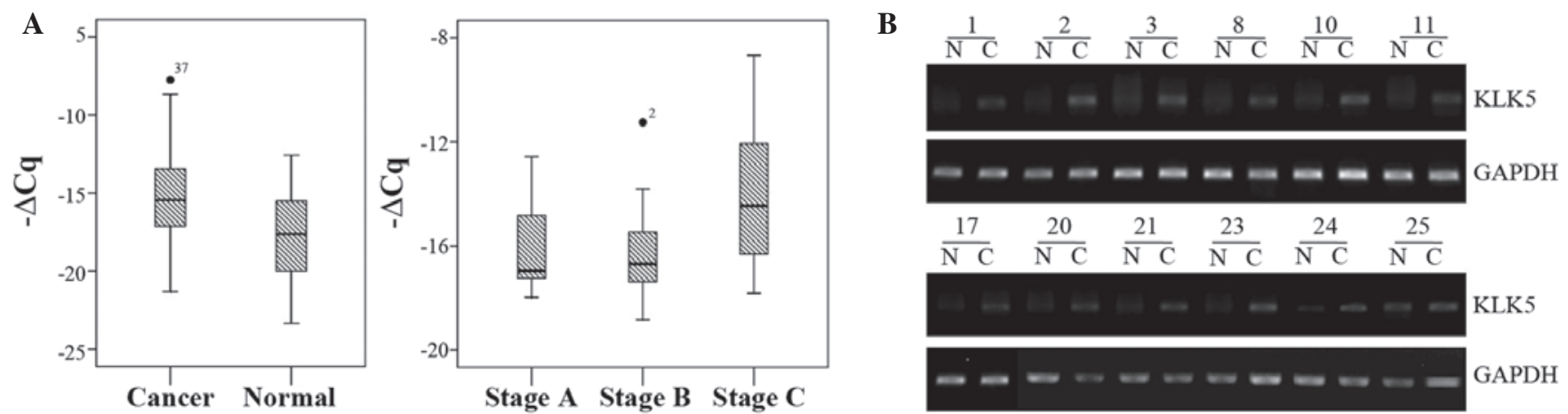

Figure 1. Upregulation of kallikrein-related peptidase 5 (KLK5) mRNA in colorectal cancer (CRC) tissues. (A) Reverse transcription-quantitative polymerase chain reaction (RT-qPCR) analysis of KLK5 mRNA expression levels in paired cancerous $(\mathrm{n}=40)$ and normal $(\mathrm{n}=40)$ tissues $(\mathrm{P}<0.001)$, and stages A-C $(\mathrm{n}=10,11,17$, respectively) of the disease ( $\mathrm{P}<0.001$ vs. the normal samples) (stars indicate the extreme value and the numbers represent the corresponding sample number). (B) Agarose gel of the KLK5 and GAPDH RT-qPCR products from representative colorectal cancer tissue samples and the corresponding normal colorectal mucosa samples $(\mathrm{N})$ (numbers above the gel indicate the initial subsequence of the specimen). GAPDH exhibited a consistent pattern of expression in all samples, indicating the integrity of the RNA and equal loading.

ELISA. A monoclonal anti-KLK5 antibody generated in our laboratory (22) was used to coat 96-well white polystyrene plates in PBS (750 ng/well) overnight at $4^{\circ} \mathrm{C}$. Subsequently, the plates were washed three times with PBS plus $0.5 \%$
Tween 20 (PBS-T), and diluted serum samples or calibrators (100 $\mu \mathrm{l} /$ well; Sino Biological, Inc., Beijing, China) were added to each well and incubated at $37^{\circ} \mathrm{C}$ for $1 \mathrm{~h}$. The plate was then washed a further six times with PBS-T. Subsequently, 

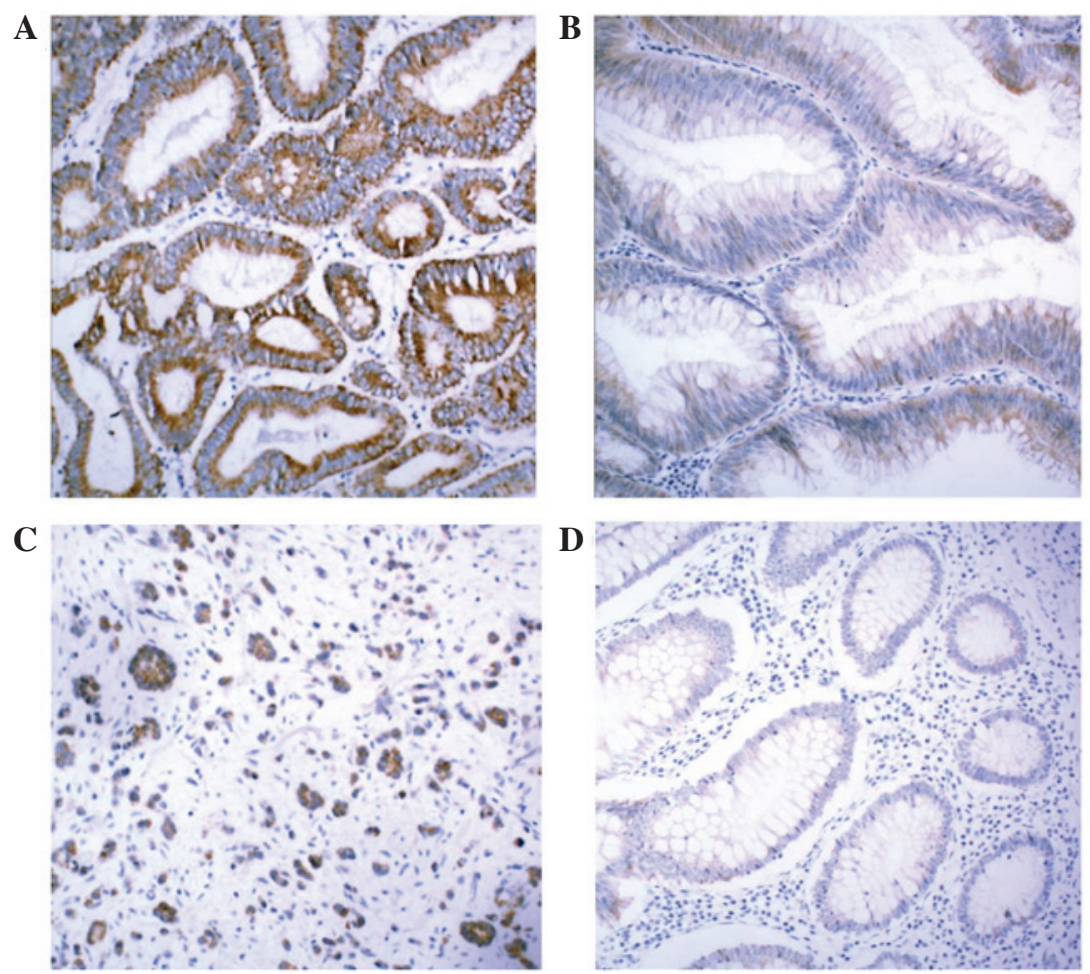

Figure 2. Immunohistochemical analysis of kallikrein-related peptidase 5 (KLK5) protein expression in colorectal cancer (CRC) and normal tissues. (A) Well-differentiated CRC; (B) adenoma; (C) poorly differentiated CRC; (D) normal colonic mucosa. KLK5 protein was upregulated in well-differentiated and poorly differentiated CRC tissues, and KLK5 staining was weak or negative in adenoma and normal colonic mucosa tissues. Magnification, x200.
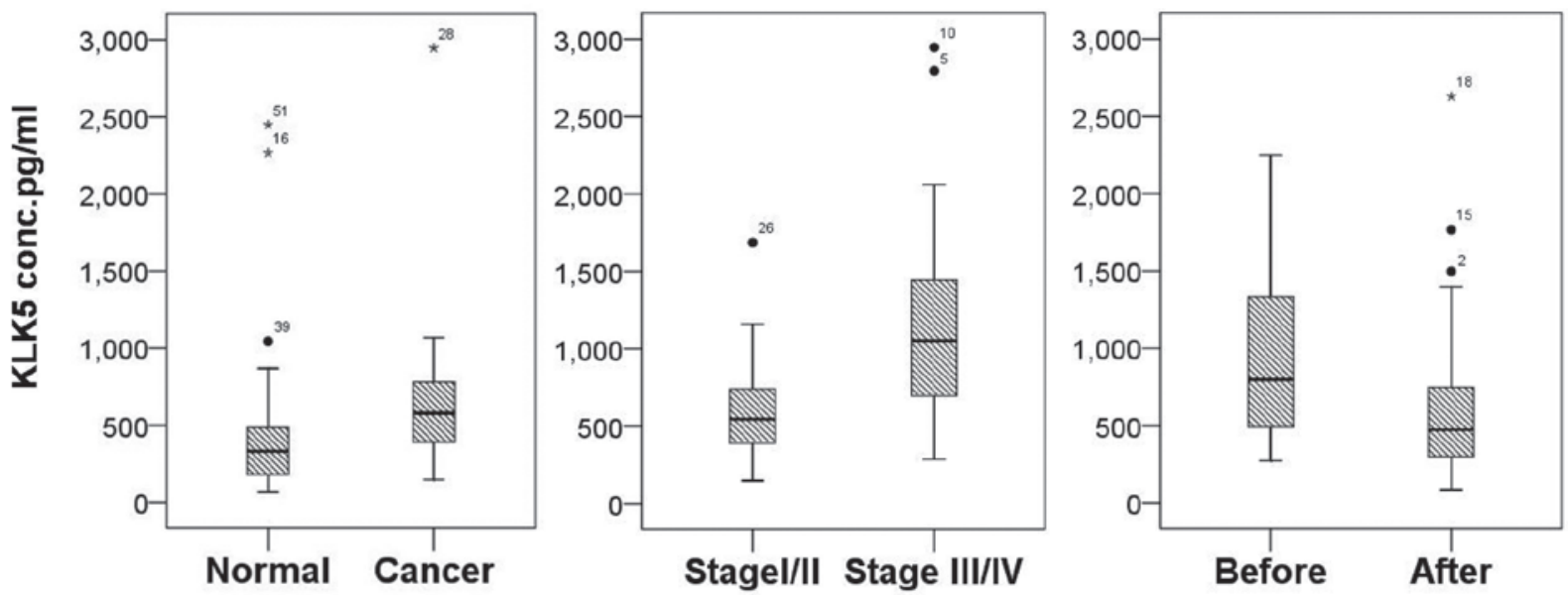

Figure 3. Enzyme-linked immunosorbent assay (ELISA) analysis of serum kallikrein-related peptidase 5 (KLK5) levels in patients with colorectal cancer $(\mathrm{CRC})$ and healthy controls $(\mathrm{P}<0.001)$. KLK5 protein concentrations were determined in sera from patients with $\mathrm{CRC}(\mathrm{cancer}$; stages $\mathrm{I} / \mathrm{II}$ and III/IV; $\mathrm{P}=0.004)$ and healthy controls (normal), including pre-surgery (before) and post-surgery (after) samples from patients with $\mathrm{CRC}(\mathrm{P}<0.001)$ (stars indicate the extreme value and the numbers represent the corresponding sample number).

$100 \mu l$ horseradish peroxidase-conjugated rabbit anti-KLK5 antibody ( $1 \mathrm{mg} / \mathrm{ml}$, diluted 1,000-fold in PBS; generated in our laboratory) was added to each well and incubated at $37^{\circ} \mathrm{C}$ for $40 \mathrm{~min}$. After washing six times with PBST, $100 \mu$ l chromogen (Tetramethylbenzidine) was added to each well and the plates were incubated at $37^{\circ} \mathrm{C}$ for $10 \mathrm{~min}$. After quenching the reaction with $50 \mu \mathrm{l} 2 \mathrm{M} \mathrm{H}_{2} \mathrm{SO}_{4}$, the absorbance (optical density) was measured at $450 \mathrm{~nm}$ using a SpectraMax M2 Multi-Mode microplate reader (Molecular Devices LLC, Sunnyvale, CA, USA).
Statistical analysis. All statistical analyses were performed using the SPSS software package, version 17.0 (SPSS Inc., Chicago, IL, USA). The serum KLK5 levels in healthy individuals compared with patients with CRC and the differences in various stages were analyzed with the Mann-Whitney U test. The serum KLK5 levels were analyzed by Wilcoxon test in patients prior to surgery and were compared with results following the surgery. The differences in expression of KLK5 mRNA in CRC and normal tissues were analyzed by Wilcoxon test. Receiver operating characteristic (ROC) 
curves were performed to analyze the data of CEA and serum KLK5 levels. The ROC curves were delineated using Sigmaplot 11.0 (Systat Software Inc., Chicago, IL, USA). Data are expressed as the mean \pm standard deviation. $\mathrm{P}<0.05$ (two-sided) was considered to indicate a statistically significant difference.

\section{Results}

KLK5 mRNA expression is upregulated in CRC tissues. The present study initially assessed the mRNA expression levels of KLK5 in 40 tumor and paired normal tissue samples from patients with CRC. The mRNA expression levels of KLK5 were upregulated in CRC tissues, as compared with in the paired normal controls (Fig. 1), and 32/40 CRC tissue samples (80\%) exhibited increased KLK5 expression. In addition, the upregulated KLK5 levels were associated with advanced tumor stages (stage $\mathrm{C} / \mathrm{D}$ vs. stage $\mathrm{A} / \mathrm{B} ; \mathrm{P}<0.001$; Fig. 1).

KLK5 protein expression is upregulated in CRC tissues and sera. The present study also assessed the protein expression levels of KLK5, since mRNA expression does not necessarily correlate with protein abundance. Immunohistochemical staining of KLK5 was performed in 48 CRC samples. KLK5 protein was highly expressed in cancerous lesions but not in normal tissues (Fig. 2A-D).

The present study also analyzed the KLK5 levels in serum samples from 70 patients with CRC and 53 healthy individuals. Among the 70 CRC serum samples, there were 38 paired pre- and post-surgery serum samples taken from patients with CRC. The serum levels of KLK5 were upregulated in patients with CRC, as compared with in the healthy controls $(878.02 \pm 602.02$ vs. $391.07 \pm 331.13 \mathrm{pg} / \mathrm{ml}$; $\mathrm{P}<0.001$; Fig. 3). The serum KLK5 levels were also significantly higher in patients prior to surgery compared with after surgery $(909.48 \pm 536.72$ vs. $644.00 \pm 522.87 \mathrm{pg} / \mathrm{ml} ; \mathrm{P}<0.001)$. Furthermore, the serum levels of KLK5 were higher in stage III/IV CRC than in stage I/II CRC (1153.56 \pm 679.97 vs. 737.91.23 $\pm 500.53 \mathrm{pg} / \mathrm{ml} ; \mathrm{P}=0.004)$.

Finally, ROC curve analysis revealed the significant and the independent value of the KLK5 expression, for the discrimination of the CRC from the normal individuals. The curve demonstrated that serum KLK5 levels [area under the curve (AUC), 0.81; 95\% confidence interval (CI), 0.7375-0.8919; $\mathrm{P}<0.001]$ exhibited a significant discriminatory value in the whole population (Fig. 4), compared to that of CEA (AUC, 0.77; 95\% CI, 0.6901-0.8533; P<0.001). No significant difference was observed between the KLK5 and CEA curves $(\mathrm{P}=0.462)$.

Association of KLK5 expression with clinicopathological features of patients with CRC. The association between KLK5 expression and clinicopathological characteristics is summarized in Tables I and II. There were significant associations between serum KLK5 levels and CRC lymph node or distant metastasis $(\mathrm{P}=0.003)$, TNM stage $(\mathrm{P}=0.004)$, and Dukes' stage $(\mathrm{P}=0.005)$ (Table I); whereas the mRNA expression levels of KLK5 in CRC tissues were associated with a high Dukes' stage $(\mathrm{P}<0.001$; Table II).

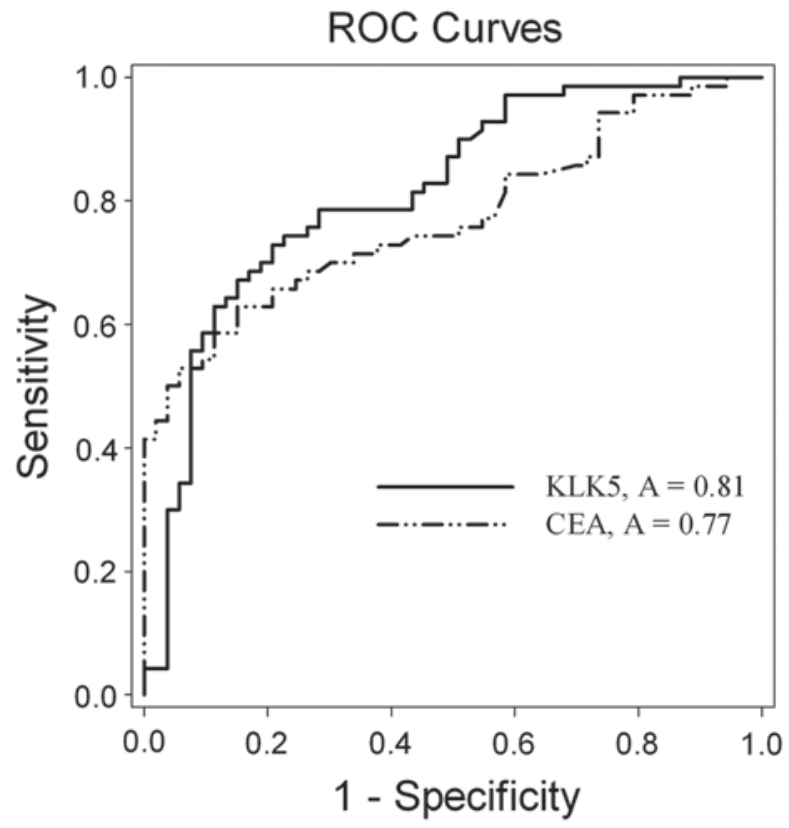

Figure 4. Receiver operating characteristic (ROC) curve analysis of serum kallikrein-related peptidase 5 (KLK5) and carcinoembryonic antigen (CEA) levels. KLK5, 95\% confidence interval (CI), 0.7375-0.8919; CEA, 95\% CI, 0.6901-0.8533 ( $\mathrm{P}=0.462)$.

Table II. Association of KLK5 mRNA expression with the clinicopathological features of colorectal cancer.

\begin{tabular}{lccc}
\hline Characteristics & $\mathrm{N}$ & $\begin{array}{c}\text { KLK5 mRNA } \\
\text { level }(\Delta \mathrm{Cq})\end{array}$ & P-value \\
\hline $\begin{array}{l}\text { Gender } \\
\text { Male }\end{array}$ & 23 & $-15.2 \pm 2.48$ & 0.436 \\
$\begin{array}{l}\text { Female } \\
\text { Age }\end{array}$ & 17 & $-14.4 \pm 3.08$ & \\
$\quad<60$ years old & 20 & $-14.40 \pm 2.82$ & 0.224 \\
$\geq 60$ years old & 20 & $-15.30 \pm 2.64$ & \\
$\begin{array}{l}\text { Tumor site } \\
\text { Rectum }\end{array}$ & 22 & $-14.79 \pm 3.02$ & 0.913 \\
Colon & 18 & $-14.94 \pm 2.43$ & \\
$\begin{array}{l}\text { Differentiation } \\
\text { Well/moderate }\end{array}$ & 32 & $-15.00 \pm 2.84$ & 0.295 \\
$\begin{array}{l}\text { Poor } \\
\text { Tumor size }\end{array}$ & 8 & $-14.27 \pm 2.39$ & \\
$<5 \mathrm{~cm}$ & 16 & $-14.81 \pm 3.34$ & 0.699 \\
$\geq 5 \mathrm{~cm}$ & 24 & $-14.88 \pm 2.33$ & \\
$\begin{array}{l}\text { Dukes' stage } \\
\text { A/B }\end{array}$ & 21 & $-16.23 \pm 1.94$ & \\
$\mathrm{C} / \mathrm{D}$ & 19 & $-13.34 \pm 2.73$ & \\
\hline
\end{tabular}

Cq, cycle quantification.

\section{Discussion}

Early clinical detection of CRC typically relies on endoscopy 
and pathological analysis of tissue samples, which is expensive and invasive. Studies regarding CRC biomarker discovery have made little progress, possibly due to a lack of sensitive and specific tumor markers $(3,4,6)$. To date, CEA and CA19-9 remain the only widely used serum tumor markers in the early detection or prediction of treatment response in CRC (24). The present study assessed KLK5 expression in CRC tissue and serum samples using RT-qPCR, immunohistochemistry, and ELISA using our own anti-KLK5 antibody. The results demonstrated that the mRNA and protein expression levels of KLK5 were significantly upregulated in independent CRC tissue and serum samples, as compared with in normal samples. As a biomarker, KLK5 exhibited a better ROC curve than CEA. In addition, KLK5 expression was associated with malignant CRC behavior. The results of the present study indicated that KLK5 may be considered a useful biomarker for CRC. However, further studies are required to confirm these findings.

Dysregulated expression of various KLKs has been detected in a large number of human malignancies during development and progression of the disease. Therefore, the detection of KLK levels may serve as a novel and useful tumor biomarker for the early detection and monitoring of progression in patients with cancer $(25,26)$. Among these KLKs, KLK5 is important since it can activate other KLKs. A previous study reported that upregulation of KLK5 in ovarian cancer tissues was associated with advanced stages and grades of the disease, and shorter disease-free and overall survival rates of patients (27). In addition, another previous study identified a novel variant of the KLK5 5'-untranslated region due to alternative splicing, which was able to contribute to differential KLK5 expression in prostate and ovarian cancer (28). This finding indicated that KLK5-SV1 may have clinical use in various malignancies, and should be further explored as a potential novel biomarker for prostate and ovarian cancer (28). It has previously been shown that KLK6 and KLK10 are significantly upregulated in patients with $\mathrm{CRC}$, and that their upregulation is associated with a poor prognosis $(29,30)$. The present study detected the upregulation of KLK5 mRNA and protein in CRC tissues and in sera from patients with CRC, thus indicating that KLK5 may be a useful biomarker for the early diagnosis of CRC.

However, the potential mechanism underlying KLK5 activity in CRC development and progression remains to be elucidated. KLK5 was originally discovered in the epidermis and has functions related to keratinocyte turnover (desquamation), during which this serine protease can digest the extracellular matrix and increase cell mobility (8). Nevertheless, it is currently unknown why and how KLK5 is upregulated in CRC tissues and in sera from patients with CRC. Previous studies have indicated that altered microRNA expression may lead to the upregulation of KLK5 $(31,32)$, and our unpublished data support this notion.

The present study demonstrated that upregulated KLK5 levels may promote CRC development and progression. In addition, after surgery, serum KLK5 levels were downregulated, thus suggesting that KLK5 may be used to monitor CRC recurrence, metastasis, and treatment response. However, the present study does have some limitations; for example, survival or treatment data was not collected from all of the patients with $\mathrm{CRC}$, in order to determine the association with prognosis or treatment response. Furthermore, the sample size was relatively small and the conclusion needs to be veri- fied in a study with a larger sample size. Future studies will focus on the following: Function of KLK5 in CRC cells and the underlying molecular mechanism; evaluation of KLK5 as a novel biomarker for early detection, tumor progression, and treatment response of patients with CRC; and the mechanisms underlying KLK5 upregulation in patients with CRC.

\section{Acknowledgements}

The authors would like to thank the patients and healthy controls that participated in the present study. This study was supported in part by a grant from Medjaden Bioscience Limited.

\section{References}

1. Jemal A, Siegel R, Ward E, Hao Y, Xu J, Murray T and Thun MJ: Cancer statistics, 2008. CA Cancer J Clin 58: 71-96, 2008.

2. McCracken M, Olsen M, Chen MS Jr, Jemal A, Thun M, Cokkinides V, Deapen D and Ward E: Cancer incidence, mortality, and associated risk factors among asian americans of chinese, filipino, vietnamese, korean, and Japanese ethnicities. CA Cancer J Clin 57: 190-205, 2007.

3. Sarela AI:Systematic review of genetic influences on the prognosis of colorectal cancer (Br J Surg 2004; 91: 1275-1291). Brit J Surg 91: 1275-1291, 2004.

4. Duffy MJ, van Dalen A, Haglund C, Hansson L, Klapdor R, Lamerz R, Nilsson O, Sturgeon C and Topolcan O: Clinical utility of biochemical markers in colorectal cancer: European Group on Tumor Markers (EGTM) guidelines. Eur J Cancer 39: 718-727, 2003.

5. Thomas SN, Tong Z, Stebe KJ and Konstantopoulos K: Identification, characterization and utilization of tumor cell selectin ligands in the design of colon cancer diagnostics. Biorheology 46: 207-225, 2009.

6. Hammarström S: The carcinoembryonic antigen (CEA) family: Structures, suggested functions and expression in normal and malignant tissues. Semin Cancer Biol 9: 67-81, 1999.

7. Borgoño CA, Michael IP and Diamandis EP: Human tissue kallikreins: Physiologic roles and applications in cancer. Mol Cancer Res 2: 257-280, 2004

8. Yousef GM and Diamandis EP: The new kallikrein-like gene, KLK-L2. Molecular characterization, mapping, tissue expression, and hormonal regulation. J Biol Chem 274: 37511-37516, 1999.

9. Brattsand $\mathrm{M}$ and Egelrud T: Purification, molecular cloning, and expression of a human stratum corneum trypsin-like serine protease with possible function in desquamation. J Biol Chem 274: 30033-30040, 1999.

10. Michael IP, Pampalakis G, Mikolajczyk SD, Malm J, Sotiropoulou G and Diamandis EP: Human tissue kallikrein 5 is a member of a proteolytic cascade pathway involved in seminal clot liquefaction and potentially in prostate cancer progression. J Biol Chem 281: 12743-12750, 2006.

11. Michael IP, Sotiropoulou G, Pampalakis G, Magklara A, Ghosh M, Wasney G and Diamandis EP: Biochemical and enzymatic characterization of human kallikrein 5 (hK5), a novel serine protease potentially involved in cancer progression. J Biol Chem 280: 14628-14635, 2005.

12. Ohler A, Debela M, Wagner S, Magdolen V and Becker-Pauly C: Analyzing the protease web in skin: Meprin metalloproteases are activated specifically by KLK4, 5 and 8 vice versa leading to processing of proKLK 7 thereby triggering its activation. Biol Chem 391: 455-460, 2010.

13. Diamandis EP and Yousef GM: Human tissue kallikreins: A family of new cancer biomarkers. Clin Chem 48: 1198-1205, 2002.

14. Kim H, Scorilas A, Katsaros D, Yousef GM, Massobrio M, Fracchioli S, Piccinno R, Gordini G and Diamandis EP: Human kallikrein gene 5 (KLK5) expression is an indicator of poor prognosis in ovarian cancer. Br J Cancer 84: 643-650, 2001.

15. Yousef GM, Scorilas A, Kyriakopoulou LG, Rendl L, Diamandis M, Ponzone R, Biglia N, Giai M, Roagna R, Sismondi P and Diamandis EP: Human kallikrein gene 5 (KLK5) expression by quantitative PCR: An independent indicator of poor prognosis in breast cancer. Clin Chem 48: 1241-1250, 2002. 
16. Avgeris M, Papachristopoulou G, Polychronis A and Scorilas A Down-regulation of kallikrein-related peptidase 5 (KLK5) expression in breast cancer patients: A biomarker for the differential diagnosis of breast lesions. Clin Proteomics 8: 5, 2011.

17. Yousef GM, Obiezu CV, Jung K, Stephan C, Scorilas A and Diamandis EP: Differetial expression of kallikrein gene 5 in cancerous and normal testicular tissues. Urology 60: 714-718, 2002.

18. Yousef GM, Polymeris ME, Grass L, Soosaipillai A, Chan PC, Scorilas A, Borgoño C, Harbeck N, Schmalfeldt B, Dorn J, et al: Human kallikrein 5: A potential novel serum biomarker for breast and ovarian cancer. Cancer Res 63: 3958-3965, 2003.

19. Korbakis D, Gregorakis AK and Scorilas A: Quantitative analysis of human kallikrein 5 (KLK5) expression in prostate needle biopsies: An independent cancer biomarker. Clin Chem 55: 904-913, 2009.

20. Sotiropoulou G, Pampalakis G and Diamandis EP: Functional roles of human kallikrein-related peptidases. J Biol Chem 284 32989-32994, 2009.

21. Talieri M, Li L, Zheng Y, Alexopoulou DK, Soosaipillai A, Scorilas A, Xynopoulos D and Diamandis EP: The use of kallikrein-related peptidases as adjuvant prognostic markers in colorectal cancer. Br J Cancer 100: 1659-1665, 2009.

22. Wu Y, Liu X, Chen Y and Hu C: Development and evaluation of an ELISA method for the measurement of kallikrein-related peptidase 5 (KLK5) in human serum. Open J Clin Diagn 3: $159-166,2013$

23. Fan X, Liu B, Xu H, Yu B, Shi S, Zhang J, Wang X, Wang J, $\mathrm{Lu} \mathrm{Z}, \mathrm{Ma} \mathrm{H}$ and Zhou X: Immunostaining with EGFR mutation-specific antibodies: a reliable screening method for lung adenocarcinomas harboring EGFR mutation in biopsy and resection samples. Human Pathology 44: 1499-1507, 2013.

24. Anthony T, Simmang C, Hyman N, Buie D, Kim D, Cataldo P, Orsay C, Church J, Otchy D, Cohen J, et al; Standards Practice Task Force, The American Society of Colon and Rectal Surgeons: Practice parameters for the surveillance and follow-up of patients with colon and rectal cancer. Dis Colon Rectum 47: 807-817, 2004.
25. Avgeris M, Mavridis K and Scorilas A: Kallikrein-related peptidase genes as promising biomarkers for prognosis and monitoring of human malignancies. Biol Chem 391: 505-511, 2010.

26. Mavridis K and Scorilas A: Prognostic value and biological role of the kallikrein-related peptidases in human malignancies. Future Oncol 6: 269-285, 2010.

27. Diamandis EP, Borgoño CA, Scorilas A, Yousef GM, Harbeck N, Dorn J, Schmalfeldt B and Schmitt M: Immunofluorometric quantification of human kallikrein 5 expression in ovarian cancer cytosols and its association with unfavorable patient prognosis. Tumour Biol 24: 299-309, 2003.

28. Kurlender L, Yousef GM, Memari N, Robb JD, Michael IP, Borgoño C, Katsaros D, Stephan C, Jung K and Diamandis EP: Differential expression of a human kallikrein 5 (KLK5) splice variant in ovarian and prostate cancer. Tumor Biol 25: 149-156, 2004.

29. Kim JT, Song EY, Chung KS, Kang MA, Kim JW, Kim SJ, Yeom YI, Kim JH, Kim KH and Lee HG: Up-regulation and clinical significance of serine protease kallikrein 6 in colon cancer. Cancer 117: 2608-2619, 2011.

30. Talieri M, Alexopoulou DK, Scorilas A, Kypraios D, Arnogiannaki N, Devetzi M, Patsavela M and Xynopoulos D: Expression analysis and clinical evaluation of kallikrein-related peptidase 10 (KLK10) in colorectal cancer. Tumor Biol 32: 737-744, 2011

31. White NM, Bui A, Mejia-Guerrero S, Chao J, Soosaipillai A, Youssef Y, Mankaruos M, Honey RJ, Stewart R, Pace KT, et al: Dysregulation of kallikrein-related peptidases in renal cell carcinoma: Potential targets of miRNAs. Biol Chem 391: 411-423, 2010

32. White NM, Chow TF, Mejia-Guerrero S, Diamandis M, Rofael Y, Faragalla H, Mankaruous M, Gabril M, Girgis A and Yousef GM: Three dysregulated miRNAs control kallikrein 10 expression and cell proliferation in ovarian cancer. Br J Cancer 102: 1244-1253, 2010 . 